\section{OP0062 ASSESSMENT OF BIOTHERAPIES' EFFICACY IN BLAU SYNDROME: DATA FROM AN INTERNATIONAL RETROSPECTIVE COHORT OF 23 CASES}

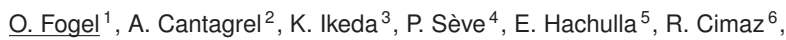
P. Sfriso ${ }^{7}$, L. Punzi ${ }^{7}$, C. Pajot ${ }^{8}$, E. Grouteau ${ }^{8}$, S. Tellier ${ }^{8}$, C. Galeotti ${ }^{9}$, S. Grotto ${ }^{10}$, J. Sibilia ${ }^{11}$, B. Bodaghi ${ }^{12}$, I. Touitou ${ }^{13}$, C. Miceli-Richard ${ }^{1}$. ${ }^{1}$ Hopital Cochin, paris; ${ }^{2}$ Hôpital Purpan, Toulouse, France; ${ }^{3}$ Chiba University Hospital, Chiba, Japan; ${ }^{4}$ Hopital de la Croix Rousse, Lyon; ${ }^{5}$ CHRU Lille, Lille, France;

${ }^{6}$ Anna Meyer Children's Hospital, Florence; ${ }^{7}$ University of Padova, Padova, Italy; ${ }^{8}$ Hopital des Enfants, Toulouse; ${ }^{9} \mathrm{CHU}$ Bicetre, le Kremlin Bicetre; ${ }^{10} \mathrm{CHU}$ Rouen, Rouen; ${ }^{11} \mathrm{CHRU}$ Strasbourg, Strasbourg; ${ }^{12} \mathrm{CHU}$ pitié Salpetriere, Paris; ${ }^{13} \mathrm{CHU}$ Montpellier, Montpellier, France

Background: Blau Syndrome (BS) is a rare autosomal dominant inflammatory disease characterized by early-onset granulomatous arthritis, dermatitis and recurrent uveitis (1). Mutations in the nucleotide-binding domain (NBD) of CARD15/NOD2 gene (mainly R334W, R334Q and L469F) have been identified in Blau syndrome (2). Despite advances in BS knowledge, patients' functional prognosis remains uncertain, BS potentially leading to visual impairment or joint deformities. Optimal treatments have not been determinated yet.

Objectives: To assess the efficacy of several biologic agents in this affection Methods: We conduct an observational, international, retrospective cohort of BS collecting clinical, biological and histological data.

Results: Among the twenty-three patients included in the cohort, 14 patients were treated by one or several lines of biologic agents, mostly by TNF blockers $(80 \%)$, IL1 blockers (16\%) or treatment targeting CTLA-4 (4\%). Fifty-seven percent of patients achieved remission after almost two lines of treatment (1.75 lines; $[0.8-2.7])$. Association with csDMARDs did not significantly improved response to biologics. Considering the 3 mains symptoms independently, TNF blockers were associated with a better response in case of articular or skin features but less effective in case of ocular involvement, a clinical situation in which IL-1 targeting should be preferentially chosen.

Conclusions: Biologic treatments appeared to be effective in BS but additional data prospectively collected are still needed in order to define their place in the therapeutic strategy in order to minimize functional consequences.

References:

[1] Blau EB. Familial granulomatous arthritis, iritis, and rash. The Journal of pediatrics. 1985 Nov;107(5):689-93. PubMed PMID: 4056967. Epub 1985/11/01. eng.

[2] Miceli-Richard C, Lesage S, Rybojad M, Prieur AM, Manouvrier-Hanu S, Hafner R, et al. CARD15 mutations in Blau syndrome. Nature genetics. 2001 Sep;29(1):19-20. PubMed PMID: 11528384. Epub 2001/08/31. eng.

Disclosure of Interest: None declared

DOI: 10.1136/annrheumdis-2017-eular.6660

\section{OP0063 CANAKINUMAB TREATMENT IN PATIENTS WITH COLCHICINE-RESISTANT FMF (CRFMF), HIDS/MKD AND TRAPS: EFFICACY IN THE 16 WEEKS RANDOMISED CONTROLLED PHASE AND MAINTENANCE OF DISEASE CONTROL AND SAFETY AT WEEK 40}

F. De Benedetti ${ }^{1}$, M. Gattorno ${ }^{2}$, J. Frenkel $^{3}$, I. Calvo ${ }^{4}$, M. Moutschen ${ }^{5}$, P. Quartier ${ }^{6}$, O. Kasapcopur ${ }^{7}$, S. Ozen ${ }^{8}$, A. Gül ${ }^{9}$, J. Anton ${ }^{10}$, I. Koné-Paut ${ }^{11}$ H. Lachmann ${ }^{12}$, H.M. Hoffman ${ }^{13}$, E. Ben-Chetrit ${ }^{14}$, A. Zeft ${ }^{15}$, Y. Gong ${ }^{16}$, E. Vritzali ${ }^{17}, \mathrm{G}$. Junge ${ }^{17} .{ }^{1} / R C C S$ Ospedale Pediatrico Bambino Gesú, Rome; ${ }^{2}$ G. Gaslini Institute, Genoa, Italy; ${ }^{3}$ University Medical Center, Utrecht, Netherlands; ${ }^{4}$ Hospital Universitario i Politecnic la Fe, Valencia, Spain; ${ }^{5} \mathrm{CHU}$ de Liège/University of Liège, Liège, Belgium; ${ }^{6}$ Necker-Enfants Malades Hospital, Paris, France: ${ }^{7}$ Department of Pediatric Rheumatology, Istanbul University Cerrahpasa Medical Faculty, Istanbul; ${ }^{8}$ Hacettepe University, Ankara; ${ }^{9}$ Department of Internal Medicine, Rheumatology Division, Istanbul University, Istanbul Faculty of Medicine, Istanbul, Turkey; ${ }^{10}$ Hospital Sant Joan de Déu, Barcelona, Spain; ${ }^{11}$ Hôpital Kremlin Bicetre, Paris, France; ${ }^{12}$ UK National Amyloidosis Centre, London, United Kingdom; ${ }^{13}$ University of California, la Jolla, United States; ${ }^{14}$ Rheumatology Unit, Hadassah-Hebrew University Medical Center, Jerusalem, Israel; ${ }^{15}$ Pediatrics Rheumatology, Cleveland Clinic, Cleveland, United States; ${ }^{16}$ Novartis Pharma, Shanghai, China; ${ }^{17}$ Novartis Pharma AG, Basel, Switzerland

Background: Canakinumab (CAN) is a fully human monoclonal antibody targeting $\mathrm{IL}-1 \beta$, a key cytokine in the pathogenesis of periodic fever syndromes (PFS) including familial Mediterranean fever (FMF), hyper-lgD syndrome/mevalonate kinase deficiency (HIDS/MKD) and TNF receptor-associated periodic syndrome (TRAPS).

Objectives: The CLUSTER trial (NCT02059291) studied efficacy and safety of CAN in CrFMF, HIDS/MKD and TRAPS. The primary objective was to demonstrate that CAN150 mg every 4 weeks (q4w) is superior to placebo (PBO) in resolving the flare by Day 15 with no new flares over 16 weeks (wks). Secondary objectives included the proportion of patients (pts) who maintained optimal control of disease activity (absence of new flares) between Wk 16 and Wk 40 after dose reduction. Methods: The study comprised 4 epochs (E1-E4). ${ }^{1}$ After lead-in E1, in E2 patients at time of an active fever flare were randomised to CAN $150 \mathrm{mg}$ q4w or $\mathrm{PBO}$ for 16 wks. Responders in E2 were re-randomised to $\mathrm{PBO}$ or $150 \mathrm{mg}$ q8w for 24 wks. During E3, pts who escaped to open-label CAN in E2, were similarly down-titrated to open-label CAN q8w to gain additional information on the long-term maintenance dose. In pts with a flare, dose could be escalated up to $300 \mathrm{mg} \mathrm{q4w}$. Safety assessments included adverse events (AEs) and serious AEs.

Results: The proportion of responders at Wk 16 was statistically higher with CAN vs PBO (Table). In E3, among the 41 re-randomised pts (PBO vs CAN 150 $\mathrm{mg} \mathrm{q8w)}$ the proportion of pts who did not present new flares was numerically higher in the CAN vs PBO group (Table). Overall at Wk 40 (end of E3), including re-randomised pts and pts treated in open-label, $46 \%$ of the crFMF pts, $53 \%$ of the TRAPS pts and $23 \%$ of the HIDS/MKD pts maintained disease control with $150 \mathrm{mg}$ q8w. Conversely, up-titration to $300 \mathrm{mg} \mathrm{q} 4 \mathrm{w}$ was required in $28.8 \%$ of HIDS/MKD pts, and in $10.2 \%$ and $8.3 \%$ of pts with crFMF and TRAPS, respectively. In E3, the majority of pts who received CAN had PGA $<2$, normal CRP and SAA levels in all 3 cohorts. No new safety findings nor death were reported in CAN-treated pts through E3 (Table).

\begin{tabular}{|c|c|c|c|c|c|c|c|}
\hline \multicolumn{8}{|c|}{$\begin{array}{l}\text { Table. Efficacy results and summary of safety } \\
\text { Efficacy }\end{array}$} \\
\hline \multirow{4}{*}{$\begin{array}{l}\text { Proportion of } \\
\text { responders at } \\
\text { Week 16 (E2), } \\
\mathrm{n} / \mathrm{m}(\%)\end{array}$} & \multicolumn{2}{|c|}{ Cohort } & $\begin{array}{c}\text { CAN } 150 \mathrm{mg} \mathrm{q}^{4 \mathrm{w}} \\
\mathrm{N}=90\end{array}$ & \multicolumn{2}{|l|}{$\begin{array}{l}\mathrm{PBO} \\
\mathrm{N}=91\end{array}$} & $\begin{array}{c}\text { OR } \\
(95 \% \mathrm{CD})\end{array}$ & p-value \\
\hline & \multicolumn{2}{|c|}{ crFMF } & $19 / 31(61.3)$ & \multicolumn{2}{|c|}{$2 / 32(6.3)$} & $23.8(4.4,227.5)$ & $<0.0001^{\circ}$ \\
\hline & \multicolumn{2}{|c|}{ HIDS/MKD } & $13 / 37(35.1)$ & \multicolumn{2}{|c|}{$2 / 35(5.7)$} & $8.9(1.7,86.4)$ & $<0.002^{*}$ \\
\hline & \multicolumn{2}{|c|}{ TRAPS } & $10 / 22(45.5)$ & \multicolumn{2}{|c|}{$2 / 24(8.3)$} & $92(1.5,94.6)$ & $0.005^{*}$ \\
\hline \multirow{4}{*}{$\begin{array}{l}\text { Proportion of pts } \\
\text { with no new nare } \\
\text { at Week } 40(\mathrm{E} 3) \text {, } \\
\mathrm{n} / \mathbf{m}(\%)\end{array}$} & \multicolumn{2}{|c|}{ Cohort } & $\begin{array}{c}\operatorname{CAN} 150 \mathrm{mg} q 8 w \\
N=19\end{array}$ & \multicolumn{2}{|c|}{$\begin{array}{l}\mathrm{PBO} \\
\mathrm{N}=22\end{array}$} & $\begin{array}{c}\text { OR } \\
(95 \% \mathrm{Cn})\end{array}$ & p-value \\
\hline & \multicolumn{2}{|c|}{ CrFMF } & $7 / 9(77.8)$ & \multicolumn{2}{|c|}{$3 / 10(30.0)$} & $8.2(0.8,113.4)$ & 0.0513 \\
\hline & \multicolumn{2}{|c|}{ HIDS/MKD } & $3 / 6(50.0)$ & \multicolumn{2}{|c|}{$1 / 7(14.3)$} & $6.0(0.3,366.2)$ & 0.2168 \\
\hline & \multicolumn{2}{|c|}{ TRAPS } & $3 / 4(75.0)$ & \multicolumn{2}{|c|}{$2 / 5(40.0)$} & $4.5(0.15,313.5)$ & 0.3571 \\
\hline \multicolumn{8}{|c|}{ Safety: Summary of AEs and SAEs } \\
\hline & All & \multicolumn{2}{|c|}{ CrFMF } & \multicolumn{2}{|c|}{ HIDSARD } & \multicolumn{2}{|c|}{ TRAPS } \\
\hline & $\begin{array}{l}\mathrm{PBO} \\
\mathrm{N}=24\end{array}$ & $\begin{array}{c}\text { Any CAN" } \\
\text { E2 } \\
\text { N=58 }\end{array}$ & $\begin{array}{c}\text { Any } \mathrm{CAN}^{*} \\
\mathrm{E} 2+\mathrm{E} 3 \\
\mathrm{~N}=61\end{array}$ & $\begin{array}{c}\text { Any CAN" } \\
\qquad 2 \\
N=68\end{array}$ & $\begin{array}{l}\text { AnycAN } \\
E 2+E 3 \\
N=71\end{array}$ & $\underset{\substack{\text { Eny } \\
\mathrm{N}=43}}{\operatorname{Any}}$ & $\begin{array}{c}\text { Any CAN } \\
E 2+E 3 \\
N=61\end{array}$ \\
\hline Exposure to CAN, PY & 2.0 & 16.4 & 45.6 & 19.1 & 51.0 & 12.1 & 39.2 \\
\hline Number of AEs & 34 & 134 & 332 & 251 & 613 & 112 & 265 \\
\hline AE rate $100 \mathrm{PY}$ & 1698.8 & 8167 & 728.2 & 1313.6 & 1201.2 & 925.7 & 676.2 \\
\hline Number of SAEs & 1 & 7 & 17 & 11 & 20 & 3 & 5 \\
\hline SAE rate/ $100 \mathrm{PY}$ & 50.0 & 42.7 & 37.3 & 57.6 & 39.2 & 24.8 & 12.8 \\
\hline
\end{tabular}

Conclusions: Canakinumab (150 mg q4w) was efficacious in resolving flare at Day 15 and preventing new flares over 16 wks. In the longer term (40 wks), absence of flares was maintained in more than half patients at the extended dosing interval (150 mg q8w) in the crFMF and TRAPS cohorts. A higher dose was needed in HIDS/MKD patients. No unexpected safety issues were reported over 40 wks of canakinumab treatment.

References:

[1] De Benedetti F, et al. Ann Rheum Dis. 2016;75:615-6.

Disclosure of Interest: F. De Benedetti Grant/research support from: Pfizer, AbbVie, Roche, Novartis, Novimmune and BMS, M. Gattorno Grant/research support from: Novartis and SOBI, Consultant for: Novartis and SOBI, J. Frenkel Grant/research support from: Novartis and SOBI, I. Calvo Grant/research support from: Novartis, Pfizer, AbbVie and Roche, Speakers bureau: Novartis, AbbVie, Gebro and Roche, M. Moutschen: None declared, P. Quartier Grant/research support from: AbbVie, BMS, Chugai-Roche, Novartis and Pfizer, Consultant for: AbbVie, Novartis, Servier and SOBI, Speakers bureau: AbbVie, BMS, ChugaiRoche, Medimmune, Novartis, Pfizer and SOBI, O. Kasapcopur Consultant for: Novartis, Speakers bureau: Novartis and Pfizer, S. Ozen Speakers bureau: Novartis and SOBI, A. Gül Grant/research support from: Novartis, J. Anton Grant/research support from: Novartis, Consultant for: Novartis, I. Koné-Paut Grant/research support from: Novartis, SOBI and Roche, Consultant for: Novartis, SOBI, Pfizer, AbbVie and Roche, H. Lachmann Consultant for: Novartis, SOBI, Takeda and GSK, Speakers bureau: Novartis and SOBI, H. Hoffman Consultant for: Novartis, Speakers bureau: Novartis, E. Ben-Chetrit Consultant for: Novartis, A. Zeft Shareholder of: Merck, Opko Health and Arno therapeutics, Consultant for: Novartis, Y. Gong Employee of: Novartis, E. Vritzali Employee of: Novartis, G. Junge Employee of: Novartis

DOI: 10.1136/annrheumdis-2017-eular.2194 